\title{
To Share or Not to Share? Research-Knowledge Sharing in Higher Education Institution: Preliminary Results
}

\begin{abstract}
The world has witnessed that knowledge has become a valuable resource and asset in a new economy, which demands people not only to create knowledge, but also to attain, apply and share knowledge effectively. Knowledge sharing is viewed as a natural activity in higher education institutions (HEIs), especially in pertain to its core activity, i.e. research. This study emphasises on a nature of research-knowledge sharing in a university, exploring three aspects: (1) why sharing; (2) why not sharing; and (3) what and when to share. Since there is a dearth in research examining knowledge sharing in academia, a qualitative has been employed in order to gain in-depth understanding and insights about the desired phenomenon. This study suggests that the way research-knowledge is shared does not follow a single standard pattern. The results generate original insights into the issues and have practical implications for university academics and leaders.
\end{abstract}

Keywords: explicit and tacit knowledge, knowledge sharing, research-knowledge sharing

\section{Introduction}

Many studies have sought to demonstrate a positive link between knowledge management and knowledge sharing activities with organisational performance. This is evident in both qualitative studies (see e.g. Nonaka, 1994; Davenport and Prusak, 1998; Massey et al., 2002) and quantitative studies (e.g. Simonin, 1997; Schulz and Jobe, 2001; Choi and Lee, 2003; Darroch and McNaughton, 2003). Knowledge developed from information is a distinctive, difficult to imitate and non-substitutable corporate resource (Calof, 2008), which could lead to sustainable competitive advantage. Knowledge sharing has become a centre of attention for researchers and practitioners in the knowledge management field. Despite of extensive literatures examine the issue of knowledge sharing in corporate sectors, many have disregarded the issue of knowledge sharing in HEIs contexts, specifically researchknowledge. Metcalfe (2006) suggests that the application of knowledge management (KM) in higher education has been heretofore only partially examined, and the social aspect of KM has been largely ignored in the literature. Many HEIs see the challenges to cultivate the culture of knowledge sharing in order to enhance their research profiles. This paper aims to study the nature of research-knowledge sharing among academics at universities.

The paper starts with a review of the background of knowledge, including explicit and tacit. It then discusses the knowledge sharing in corporate sectors the lack of research on research knowledge sharing in Higher education. This is followed by the research methodology - an interpretative approach with qualitative analysis. The results are discussed in three separate sections covering issues of why sharing, why not sharing, and what and when to share. The last section of the paper draws the conclusion and describes research in progress. 


\section{Literature Review}

This literature review provides essential knowledge on three relevant research areas - the knowledge overview, knowledge sharing in corporate sectors, and research-knowledge sharing in higher education institutions.

\subsection{Knowledge Overview}

The new economy stands out with a distinctively characteristics since it deals with a unique resource called "knowledge". In contrast with other traditional resources like land, labour, and capital, knowledge to a certain extent, becomes a public good, once it is distributed and shared. Knowledge is distinguished into two separate dimensions - tacit and explicit (Nonaka and Konno, 1998). Unlike "data" and "information", the concept of "knowledge" is more elusive to understand due its intangible and fuzzy nature. Blair (2002) clearly distinguishes knowledge from data and information using the following examples:

People might say,

"Put the data on the desk", or

"Get the data and fax it to New York", or

"Bill had the data, but he lost it"

or,

"Put the information on the desk", or

"Get the information and fax it to New York", or

"Mary had the information, but she misplaced it"

But would people ever say,

"Put the knowledge on the desk", or

"Get the knowledge and fax it to New York", or

"Chris had the knowledge yesterday, but lost it"

Blair makes it clear that knowledge is one.s ability to do something or to exercise a kind of expertise. He concludes that a computer can have data (e.g. facts and figures stored in the data base), a report can have information (informative) but only a person can be knowledgeable, have and exercise knowledge. Blair's definition emphasises knowledge as an intangible human asset that can be exchanged only two or more people interact.

While tacit knowledge is defined as "the expertise and assumptions that individuals develop", explicit knowledge is defined as knowledge that "has been explained, recorded or documented" (Mclnerney, 2002). It has been proposed that tacit knowledge is hidden, hard to articulate and based on individuals. experiences. According to Snowden (2008), since tacit knowledge is usually embedded in stories, this type of knowledge can only be exchanged effectively when the narratives of those stories are preserved. On the other hand, explicit knowledge can be documented, created, written down, transferred and followed verbally or through computer programs, patents, diagram or via some medium of communication such as emails, telephone, or information technologies (Choi and Lee, 2003; Akgun et al., 2005). Barth (2002) summarises explicit knowledge as knowledge that can be processed by 
information systems, codified or recorded, archived and protected by organisations. Nonaka and Takeuchi (1995) argued that explicit knowledge can be transformed into tacit knowledge through the "internalization process". In this paper, the concept of both tacit and explicit knowledge has been adopted.

Nonaka and Takeuchi.s (1995) SECI spiral model is one robust effort designed to develop ways of converting tacit knowledge into explicit and back again in a cycle mode. SECI model involves four modes of knowledge transformation. Socialisation is the "tacit-to-tacit" knowledge transformation, in which experiences or actions are shared in social ways or informal interactions. Externalisation is the "tacit-to-explicit" knowledge transformation, where an individual captures the "know-how" knowledge by writing it down or capturing it using information technologies. Combination is the "explicit-to-explicit" knowledge transformation, which happens when multiple sources of explicit knowledge are converted into more systematic sets of tangible or codified knowledge. Internalisation is the "explicitto-tacit" knowledge transformation, which often occurs when explicit knowledge is often practiced and incorporated within an individual.

While the SECI model shows several strengths, critics have discussed the shortcomings of the model. With regard to the sequential nature (i.e. moving the tacit conversions to the beginning and end of the spiral) of the SECI model, Majchrzak et al. (2004) and Thomke (1998) argued that, the conversion of tacit knowledge pass through all knowledge creation stages. Klein (2008) also argued that the development of SECI although valuable, it will not be enough to explain the conversion of knowledge. He suggests that the development of tacit knowledge requires personal facilitation, i.e. by first-hand experience: learning-by-doing. Consequently, Nonaka.s SECI model has been criticised for being unable to specify the functional relationship between the tacit and explicit sides to individual and group knowledge (e.g. Thompson and Walsham, 2004).

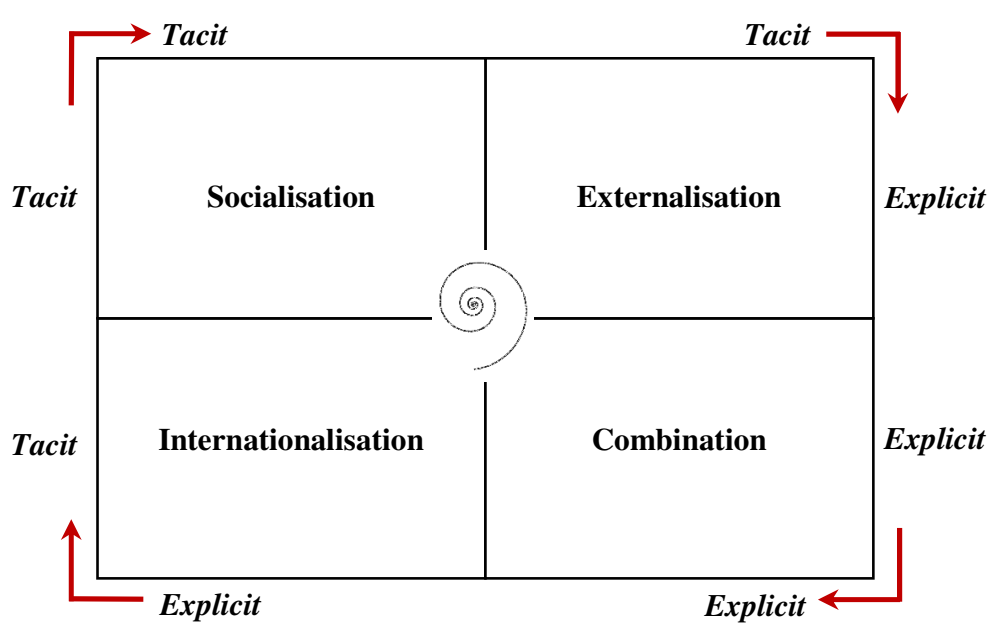

Figure 1: The SECI Model (Nonaka and Takeuchi, 1995)

\subsection{Knowledge Sharing in Corporate Sectors}

An important agenda of knowledge management initiatives is a systematic promotion of knowledge sharing among organisation members (Eisenhardt \& Martin, 2000), which is a critical area that needs more attention. Many organisations enhance knowledge sharing 
behaviour among their employees in order to achieve the organisational goals and increase performances.

The idea of knowledge sharing is about communicating and transfering knowledge, in explicit and tacit forms, within individuals or groups of people. This process may occur formally among colleagues in a workplace or informally among friends and social network. Abdullah et al. (2009) defines knowledge sharing as a process where the individual exchanges his/her knowledge and ideas through discussions or other forms of social interaction in order to create new knowledge or ideas. In other words, knowledge sharing is where individuals share what they have learned or experienced and passed what they knew to other people who may have similar interests or found the knowledge useful.

Knowledge sharing is embedded within the knowledge-process scope where knowledge is generated and put to use (Shapira et al., 2005). The sharing process consists of collecting, organizing, and conversing knowledge from one to another (Van den Hooff and Van Weenen, 2004), in which the value of knowledge expanded when it is shared. Literature shows that knowledge sharing can greatly improve work-quality, decision-making skills, problem-solving efficiency and competency (Alavi and Leidner, 1999; Salisbury, 2003; Syed-Ikhsan and Rowland, 2004; Yang 2007). Numerous researchers have established that practising knowledge sharing results in improved organisational effectiveness (Gupta and Govindarajan, 2000; Widen-Wulff and Suomi, 2003, 2007; Darroch and McNaughton, 2002, 2003). Some organisations attain competitive advantage by encouraging and promoting knowledge sharing (Liebowitz, 2001).

According to Jarvenpaa and Staples (2000), a ,willingness to share. is positively related to both profitability and productivity. Many organisations encourage knowledge sharing behaviour among their employees in order to meet the organisation.s objective and goals, including Buckman Laboratories, Texas Instruments, Dow Chemicals, and Chevron (Hawamdeh, 2003). The outcome of knowledge sharing is creation of new knowledge and innovation that will improve organisational performance.

The way of sharing knowledge has been evolving from the SECI model to new paradigm building upon pervasive computing, ubiquitous computing, context awareness, and humancentric computer interaction design, which is characterized by systems and technologies that are (Zelkha \& Epstein 1998; Aarts et al., 2001) context aware. Social capital and network theory recognises that employees do not work, learn or share knowledge in isolation but are embedded in social networks. When a formal or informal group (or communities of practice) is formed its members bring with not only their knowledge, skills, and abilities but also their social connections (Wang and Noe, 2010), including online social network (Chow and Chan, 2008) and social media (Hsu and Lin, 2008; Lin, et al 2009) - blogs, twitter, Professional Virtual Communities (PVC).

\subsection{Research-Knowledge Sharing in Higher Education Institutions}

Comparing research on knowledge sharing in the commercial sector with that in higher education, the amount in the former is disproportionate. Research becomes an essential function of higher education institutions emerged from the German model in the early 1800s (Schimank and Winnes, 2000), prior to that, teaching has been its primary function. In conjunction with economic growth since 1990s, research has become a critical driver to stay 
in parallel with knowledge-based economy. According to Stanley and Patrick (1998), although UK.s research funding mechanism has been revised in 1992, conventional research universities in the UK performing greater amount of research will acquire larger allocations of research funds from the government than other universities. Shin (2009) presents that since research is recognised as an engine for economic growth, government and higher education institutions have encouraged research supported by extensive funding programs. Good research track records are now basic requirement to recruit academics, promote and secure their place in higher education institutions. This shows the urgency of academic research in higher education institutions. In order to achieve better research productivity, higher education institutions need to build, encourage, and cultivate research-knowledge sharing among academics.

Defining "research" is a pretty much complex task, as this depends on the field of knowledge discovery, educational contexts, and the educational level in question (Chong, 2010). Chong describes research as "an investigative endeavour that aims to arrive at "new" (in a contextual sense) information or understanding, which thereby advances human (or the individual.s) knowledge, involves searching for or gathering of information, followed by interpretation or evaluation followed by interpretation or evaluation". Research comes in different forms, including scholarship, pedagogic and practice-based research, and may include some forms of consultancy. The common understanding of research in UK higher education is that scholarship is discovery of new knowledge; this refers to the traditional approaches of scientific institutions. The field of science was the object these last years of a considerable number of works, in particular around sociology of sciences and techniques (e.g. Latour, 2000; Callon, 1986), but also around the economy of knowledge (David and Foray, 2002; Von Hippel,1988) or on new forms of innovation like the open innovation (Chesbrough, 2003a;b) or E-science. For practice-based or applied research, the defining criterion is transferring knowledge to industry / market while improving understanding of the practice of a profession. This has been seen an increasing trend in the UK, schemes and initiatives include, for example, university - industry consultancy projects; Innovation Vouchers, knowledge transfer activities, knowledge transfer partnerships (KTP). There is another category of research - Pedagogic research, which is more on the impact on learning and teaching.

Higher education is a knowledge intensive sector. Research has been recognised as a key driver toward innovation, and is becoming an essential function of UK higher education institutions (Schimank and Winnes, 2000). However, study into knowledge sharing in HEI has been rather limited. In an early study, Kidwell, et al (2000) argue that education institutions need to develop initiatives to share knowledge to achieve business objectives, the approaches proposed by the researchers are limited to explicit knowledge sharing using Internet Portal technology.

\section{Research Questions}

While extensive studies investigated what drives employees to share knowledge at corporate sectors, too little is known about how academics share their research-knowledge within the university. Developing and cultivating knowledge sharing culture within a university and motivating academics to share their research-knowledge may well be one of the highest challenges for HEIs. The goal of this paper is to explore these issues and present answers to 
some questions, which will provide understanding and original insights into the particular context.

Q1 What are the types of knowledge shared in terms of research?

Q2 What are the factors that induce the sharing of research-knowledge among academics?

Q3 What are the factors that affect the sharing of research-knowledge among academics?

This paper aims to propose a research knowledge sharing model practically appropriate for higher education institution.

\section{Research Methodology}

An interpretive approach has been employed in order to answer the research questions. Through purposive sampling technique, 18 participants from one higher education institution, involving four different disciplines were interviewed. The qualitative analysis will aid understanding in more naturalistic results, giving due emphasis to both perceptual and factual data viewed and experienced of all participants. Since the area of study has not received much attention by researchers so far, the qualitative methodology has been identified as appropriate. A qualitative study can generate an in-depth understanding of the contexts and detailed data (Silverman, 1994; Yin, 1984). Chen and Hirschheim (2004) indicate that different dimensions provided by qualitative methods would not be accomplished by the positivist paradigm and survey methods. Otter (2009) states that the findings of qualitative and interpretive research is that the research have greater validity and are less artificial than quantitative research since it enables the researcher to develop a more accurate understanding of those phenomena. Walsham (1995) describes interpretive approach as a type of research that does not predefine dependent or independent variables, or set out to test hypotheses. Hence, this study applied qualitative, interpretive approach to collect information from participants involved in research-knowledge sharing activities.

\subsection{Sampling}

Two groups of academics were selected, consisting of researchers and research-leaders from four different disciplines from the Business School, in one higher education institution. Using purposive sampling approach, eleven researchers and seven research-leaders were selected. According to Neuman (1997) purposive sampling is not intended to provide generalisability of findings beyond the sample group, but it ensures that specific characteristics of the population group are relevant to the overall study purpose and research questions.

Researchers were those academics appointed on teaching and research employment, which consist of early, mid, and senior career researchers. Cheol (2011) grouped faculty members following by their age, i.e. early career (aged 39 or younger), mid career (aged 40-55) and late career (aged 56 or older). Instead of using age, this study chose to group academics using a specific career phase. Bazeley (2003) defines an early career researcher as one who is currently within their 5 years of academic or other research-related employment allowing uninterrupted, stable research development following completion of their postgraduate research training. Following the scale of five years on each career phase, the phase ranges for this study were set as: early career researcher (within 5 years of academic employment); mid researcher (within 10 years of academic employment); and senior career researcher (beyond 
10 years of academic employment). The main criterion for the selection of academics is someone who is engaged in research activities regardless of area of interests. Researchleaders, on the other hand, were those with formal leadership authority relevant to research, selected from different institution levels, ranging from university level (e.g. Pro Vice Chancellor of Research and Director of Research), faculty/school level (e.g. Dean and Associate Dean of Research), and department/subject group levels (e.g. Professors and Associate Professors).

\subsection{Data Collection}

For this part of study, 18 semi-structured interviews with researchers and research-leaders were conducted. The interviews started with open questions, on the whole inquiring participants to describe on general perspectives of the desired topic. As the interviews progressed, the questions are more structured inquiring into the "what", "why", and "when" factors. In this way, both perception and factual data were captured, which allows much thorough and systematic examination.

Unstructured follow-up questions were used as an exploratory action to encourage further explanation or to check the meaning of key words used by the interviewees. Ideally, the main purpose was to provide opportunities for the interviewees to reveal their current experience in regards to research-knowledge sharing as completely as possible. However at rare circumstances, some new non-bias examples or aspects, which have not been previously mentioned by the interviewee, were introduced aiming to trigger further discussions upon particular issues.

Interviews were recorded for the verbatim transcription purposes. The transcripts were then analysed in a repetitive manner. The processes involved repeated readings in seeking the underlying foci and intention expressed in them, comparing and contrasting transcripts for similarities and differences, and looking for key structural relationships that related or distinguished the transcripts to and from each other. Key themes started to emerge, where this brings to a shift for the analysis to an iterative process of alternating between the emerging analytic outcomes and the original transcript data. This continued until no further refinements were made, and a consistent set of categories eventuated, following repeated iterations. And finally, the desired research questions were analysed and interpreted.

\section{Results and Discussion}

In reactions to all data collected, it is found that the way research-knowledge is shared among researchers within the university does not follow a single standard pattern. This section is divided into four main categories: what and when to share, why sharing, and why not sharing. Each category is discussed with supporting evidences gained from the interviews.

\subsection{What and When Not to Share?}

Apparently, knowledge does relate to power and position of people (Alvesson and Karreman, 2001) because knowledge is the assets that are most challenging in organisations. Based on the interview with both groups, researchers and research-leaders, the issue of "stealing of 
ideas" or "plagiarisms" have risen up. The university research-leader clearly mentioned that although this scenario is not an issue in the university, it seems to be one of the most serious elements to be looked after by the university. Some embryonic ideas shared may cause to the stealing of the ideas by other researchers.
"There is definitely a danger in academia, where one gives away a lot and suddenly you find somebody.s writing a paper about your idea, which you yourself never put into a paper yet." (Professor)

Following this, this study reveals that researchers are not sharing their research-knowledge every day at all times, but sharing it only at certain point of time. Some researchers are rarely sharing their research-knowledge at the beginning of the research process, where a particular research idea is still immature or undeveloped. They tend to share their research-knowledge when the research results are configured and confirmed.

\begin{abstract}
"I don't feel like sharing my research all the times with my colleagues. I don't think they want to know what I'm doing...well, you know, not all the times. Even for me, I feel much comfortable of sharing at the last stage of my research process and not during the process. I certainly disseminate my final results."(Mid Career Researcher)

"People are sharing nothing about research content. They only share research process and so your colleagues know nothing about your research content, but they are helping you on your process. The reason is they don't share what they know or are doing. Some people don't do it because they don't want their colleagues to do well and overtake them. But mostly people just don't it." (Professor)
\end{abstract}

This paper links the "what-to-share" factor with the types of knowledge, tacit and explicit; that the researchers choose to share within the university. It found that types of knowledge shared are mixed and varied among researchers, but does not influenced by their career phase. Table 1 lists out specific number of researchers with the choice(s) of knowledge they preferred to share. The second column presents the percentages of explicit and tacit knowledge shared by researchers.

\begin{tabular}{l|l|l|l}
\hline $\begin{array}{l}\text { Types of Knowledge } \\
\text { Shared }\end{array}$ & $\begin{array}{l}\text { Percentages } \\
\text { Knowledge Shared } \\
(\%)\end{array}$ & $\begin{array}{l}\text { No. } \\
\text { Researchers }\end{array}$ & $\begin{array}{l}\text { Researcher's Career } \\
\text { Phases }\end{array}$ \\
\hline Mainly explicit & $70-80$ & 2 & Early and Mid \\
\hline Mainly tacit & $70-80$ & 2 & Mid \\
\hline Explicit and tacit & $50-50$ & 4 & Senior and Mid \\
\hline Only explicit & 100 & 3 & Senior, Early and Mid \\
\hline Only tacit & - & - & - \\
\hline
\end{tabular}

Table 1: Types of Knowledge Shared by Researchers

The findings suggest that researchers share mainly explicit knowledge for two main reasons: 1) they prefer more concrete information with verbal evidence; 2) they believe that tacit knowledge is remain tacit and can never been made explicit, unless the knowledge is discussed among those from typically the same area of interests. 
"I normally share more explicit than tacit because tacit is problematic to express...if the knowledge is actually hidden, so how to share with people?" (Early Career Researcher)

On the other hand, it is found that researchers who share mainly tacit knowledge believes that in terms of research, knowledge involved often are more tacit than explicit. They claim that, in research, the sharing of tacit knowledge will bring more benefits than explicit knowledge. They favourably share this type of knowledge through personal interactions and socialisations, where tacit knowledge can be made explicit.

"I share more tacit knowledge with people. Academic life is full of unwritten rules or tacit knowledge where you can only share that through informal interactions and working together and quite a lot of that does not happen in HE, that's what my research is shown anyway." (Mid Career Researcher)

While some researchers only share explicit knowledge researcher at large shares both explicit and tacit knowledge, because for them tacit is inseparable with explicit knowledge. They argue that one might share tacit knowledge without being aware of doing it due to the unique characteristic of tacit knowledge. Figure 2 presents the basic time frame of a research project linked with researcher's sharing pattern and types of knowledge normally shared.

"I share both tacit and explicit. For me tacit knowledge can be shared. Tacit knowledge is only tacit because that's something we.ve got and we the user we don't express it because it's inside us. But apparently if somebody needs to know that and doesn't know that, then we might make it explicit...or if other person recognises that we might have tacit knowledge that they want, they might be able to ask us and uncover it." (Senior Career Researcher)

"I believe as work into that explicit knowledge, you.re probably pulling things out which you might call tacit knowledge. This tacit knowledge was there but you have to know ways of expressing it. So for me, I believe explicit and tacit knowledge are interrelated...you cannot share one and leave the other. You.re actually sharing both without you realise it. (Early Career Researcher)

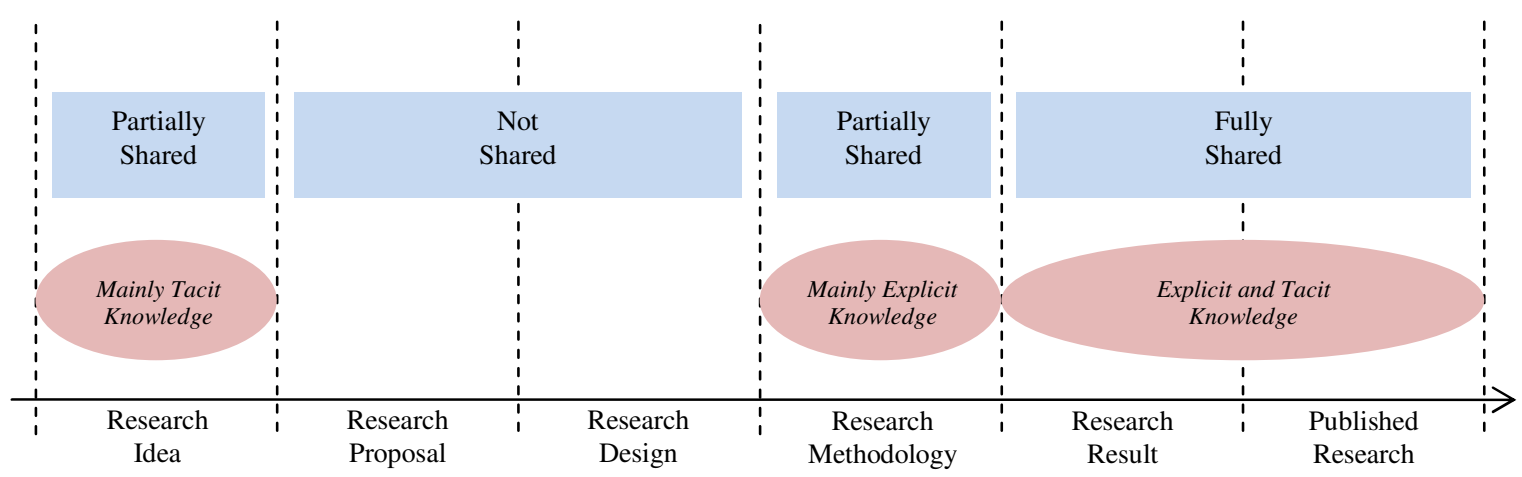

Figure 2: Link between a research timeline and types of knowledge shared

The results suggest that there are certain conditions followed by the researchers when sharing their research knowledge. Some of researchers happy to share their research ideas with other people, and those ideas normally are those of tacit knowledge, which is what embedded in their mind. However, some of them do not share at this stage because they have fear their "pearl" and undeveloped ideas might be stolen by other researchers who are more experienced in research. Researchers choose not to share their research-knowledge during the 
main process of a research projects, i.e. research proposal and research design as they believe at these stages are critical for a research project. When developing a research method, some researchers find it is useful to discuss it with other people, especially the people who are experts in a particular research technique. And they apparently share their final output with people. This paper suggests that the time frame of a research project is an influential factor that weakens the sharing pattern of research-knowledge among researchers. Researchknowledge sharing is likely to occur on interval basis. One research-leader clearly addressed the issues of "what not to share" and "when not to share".

\begin{abstract}
"In the process of doing the research, for me I rather stay alone and not share it with anyone else. I only share on some occasional circumstances. I will go to my colleagues and talk about my research methods." (Senior Career Researcher)
\end{abstract}

"I don't feel like sharing my research all the times with my colleagues. I don't think they want to know what I'm doing...well, you know, not all the times. Even for me, I feel much comfortable of sharing at the last stage of my research process and not during the process. I certainly disseminate my final results." (Mid Career Researcher)

"People don't normally share research process and the reason is they don't share what they know or are doing. Some people don't do it because they don't want their colleagues to overtake them. Yeah, mostly people just don't it." (Professor)

\title{
5.2 Why Sharing?
}

Based on the qualitative study exploring the first aspect, this study revealed mixed results. Regardless of career phase, researchers agreed that the importance of research-knowledge in academia is to the utmost. The whole idea of research activities for them is to find out things and then to share, which they perceived it as a fundamental part embedded within the whole process of a research. Apparently, these view bring a reflective idea that without sharing of knowledge, a particular research might fail or ineffective.

"First of all, if you.re a researcher, the most important thing that you need to do to find new knowledge or making contribution to knowledge, identify things which we don't know yet about and to contribute ideas in the area. Obviously, if that's you want to do, there's no point in adding to knowledge if you don't share what you have learned. Second, if you are a researcher the way that you get credit for your labour is by sharing your work through disseminating it. So the very process of writing journal article or conference papers is the form of knowledge sharing and this process is undoubtedly very important for us." (Mid Career Researcher)

Simultaneously, research-leaders also unite their views with most of them clearly used the word crucial to describe the degree of importance of research-knowledge sharing in academia. Unless researchers share their research-knowledge, the higher education could not go any forward in terms of research, and it is especially important with younger entry level post. There are two significantly basic roles of research-knowledge sharing in the university environment: to let other people know what an individual or a group of people is doing; and to inspire other people to do research and to build up their knowledge. In accordance to their leadership functions, research-leaders point out the significant role of university research culture that may substantially affect research-knowledge sharing process. When there is a dominant culture work environment, it tends to be more enjoyable and employees' morale 
boosts and this can lead to increase levels of sharing information, openness to new ideas and teamwork (Sadri \& Lees, 2001).

"I think knowledge sharing if we.re looking at both tacit and explicit it is very important among academics and also important to the outside world to know that we do that. It is very crucial because sharing knowledge is not the end result but people share knowledge in order to achieve something higher. And this is the culture that we are aiming at, not a silo working culture. Sometimes it is difficult to measure the effectiveness of knowledge sharing as the results are to be seen in the longer term and is hard to measure at this stage where it needs to be sustained. But at the end of it, the outcomes will be seen and measured." (Faculty/School Research-Leader)

Result shows that there are six core drivers, which positively induce researchers to engage in research-knowledge sharing. These data were gained from both groups: researchers and research- leaders. Table 2 summarises each driver together with the total number of times same comments were made and sample of evidences.

\begin{tabular}{|c|c|c|}
\hline Drivers & $\begin{array}{l}\text { No. of Times } \\
\text { Commented }\end{array}$ & Sample of Evidences \\
\hline $\begin{array}{l}\text { Sharing of } \\
\text { Research- } \\
\text { Knowledge for } \\
\text { Fulfilling } \\
\text { Academic } \\
\text { Requirements }\end{array}$ & (2) & $\begin{array}{l}\text { "I am not being forced, but I am voluntarily sharing knowledge as } \\
\text { my contribution to the university." (Senior Career Researcher) } \\
\text { "It is my academic duty and contributions to the university. I am } \\
\text { helping the body of knowledge and so sharing knowledge and } \\
\text { translate that into research papers is critical. It is my morale duty to } \\
\text { help the university by publishing paper." (Early Career Researcher) } \\
\text { "...it is a fantastic opportunity in terms of performing my teaching. } \\
\text { Making sure that my teaching stuff is up-to-date." (Early Career } \\
\text { Researcher) }\end{array}$ \\
\hline $\begin{array}{l}\text { Sharing of } \\
\text { Research- } \\
\text { Knowledge for } \\
\text { Self-Interest }\end{array}$ & 5 & $\begin{array}{l}\text { "People have intellectual curiosity. Even if it is not in my area, but I } \\
\text { want to know what other people are doing. So for me talking is a } \\
\text { very straight forward way where you can know and learn about them } \\
\text { and what they're doing. I can know about different perspectives, } \\
\text { methodologies or philosophies of thinking and this will help me } \\
\text { better understand my own research." (Early Career Researcher) }\end{array}$ \\
\hline $\begin{array}{l}\text { Sharing of } \\
\text { Research- } \\
\text { Knowledge for } \\
\text { Research } \\
\text { Productivity }\end{array}$ & 5 & $\begin{array}{l}\text { "The outcome I expect from my staff when they share knowledge in } \\
\text { terms of research is first, sustainability in terms of research and } \\
\text { obviously this is one benefit of having knowledge sharing. And } \\
\text { second, more outcomes. We believe that when people work together } \\
\text { the outcomes are double or triple or more than that." (Faculty/School } \\
\text { Research-Leader) } \\
\text { "Knowledge sharing is expected to lift the general quality of research } \\
\text { outputs." (Department/Subject Group Research-Leader) }\end{array}$ \\
\hline $\begin{array}{l}\text { Sharing of } \\
\text { Research- } \\
\text { Knowledge for } \\
\text { Establishing } \\
\text { Oneself as a } \\
\text { Researcher }\end{array}$ & 5 & $\begin{array}{l}\text { "When I share knowledge with people, I gained more confident with } \\
\text { my own research and at the same time they are supporting me in my } \\
\text { research. This is what I am looking for in knowledge sharing." (Early } \\
\text { Career Researcher) } \\
\text { "I always like to look for co-authors. Through knowledge sharing I } \\
\text { can find people with similar interest, have different background or } \\
\text { expertise. This is good to generate more creative thinking in terms of } \\
\text { research and it is for future research." (Early Career Researcher) }\end{array}$ \\
\hline
\end{tabular}




\begin{tabular}{|c|c|c|}
\hline $\begin{array}{l}\text { Sharing of } \\
\text { Research- } \\
\text { Knowledge for } \\
\text { Fulfilling } \\
\text { University } \\
\text { Requirements }\end{array}$ & 4 & $\begin{array}{l}\text { "I've being pushed to share knowledge by my department." (Early } \\
\text { Career Researcher) } \\
\text { "There is an expectation that we have to produce at least one paper a } \\
\text { year. So by sharing knowledge I hope to meet this expectation." } \\
\text { (Mid Career Researcher) }\end{array}$ \\
\hline $\begin{array}{l}\text { Sharing of } \\
\text { Research- } \\
\text { Knowledge for } \\
\text { Career } \\
\text { Development }\end{array}$ & 2 & $\begin{array}{l}\text { "Being research-active is part of the elements that academics can be } \\
\text { promoted. So with knowledge on how to get promoted academics } \\
\text { might probably get interested to do researches and share them with } \\
\text { people. I am very concerned of the Management Progression \& } \\
\text { Career Development of the academics. I think this is the unspoken } \\
\text { knowledge in HE because nobody really tells you on how to get } \\
\text { promoted and I try to tell people all the time. I think that's a part of } \\
\text { knowledge that is utterly missing." (Professor) }\end{array}$ \\
\hline
\end{tabular}

Table 2: Six Drivers and Samples of Evidences

\subsection{Why Not Sharing?}

From the interview with the researchers, it has been evidenced that there are eleven factors appeared to weaken them from sharing their research-knowledge, recognised as "not-toshare" factors in this paper. All the factors are summarised in Table 3, following the rank from the most to the least mentioned by researchers.

\section{Not-to-Share Factors}

(7) Lack of support from research-leaders and senior researchers

(6) Fear of losing power in terms of research area

(6) Not interested to share with everyone, but only with certain group of people

(5) Lack of confidence towards own research area and project

(5) Lack of motivation to share

(4) Not interested to share all the times

(4) Lack of trust on other researchers and research-leaders

(3) No one shows interest in the existing research area and project

(2) Not enough time due to heavy teaching workloads

*The number in the bracket is the total number of times similar comments were made

\section{Table 3: Not-to-Share Factors}

Researchers regard lacking of support from researchers and senior researchers as one of the main issues that demoralise them from sharing their research-knowledge within the university. If the research-leaders engage more with the researchers, they can help to enhance the level of trust with them. Trust is proven to be the magic ingredient that links strong ties and knowledge sharing (Levin et al., 2002) and this is enabled via support and inspiration from research-leaders or senior researchers with strong established record in research.

"I think if leaders engage with staff (and on vice-versa) they can help to build up the level of trust and openness with them. So I don.t think they will feel unwilling to share 
knowledge. Leaders certainly will reduce the effects of that problem." (Mid Career Researcher)

"Lacking of leaders. support also contributes to this problem because leaders play roles to create the culture of trust that support staff feels ready to share knowledge and at the same time doing research." (Early Career Researcher)

Research suggests that if leaders, who is seen as role models exist in the area, safety knowledge and career advancement increase (Bevill and Gast, 1998; Sosik Godshalk, 2000). The interviews with research-leaders established the idea this idea of leading by example, which implies the awareness of their critical role played within the university to inspire and encourage research-knowledge sharing culture.

"For me a leader must share their knowledge first. Sort of being a role model, demonstrates to people that there.re lots of benefits of sharing knowledge and so in that way that leader is creating a culture of trust with everybody. For example, if I as a leader don.t share my knowledge with one junior staff and she waste six months just to dig for that knowledge, once she knew that I have that knowledge she will never trust me anymore. And in return, this will stop her from sharing her knowledge with someone else." (Professor)

Based on the findings, it is shown that research-leaders at the department/subject group levels are the group of people whom researcher at large seeks support from. Researchers have not referred to research-leaders at the university level as to support research-knowledge sharing culture, but recognised those at the faculty/school levels as being encouraging. Figure 3 demonstrates the basic roles of research-leaders from various levels within the higher education context.

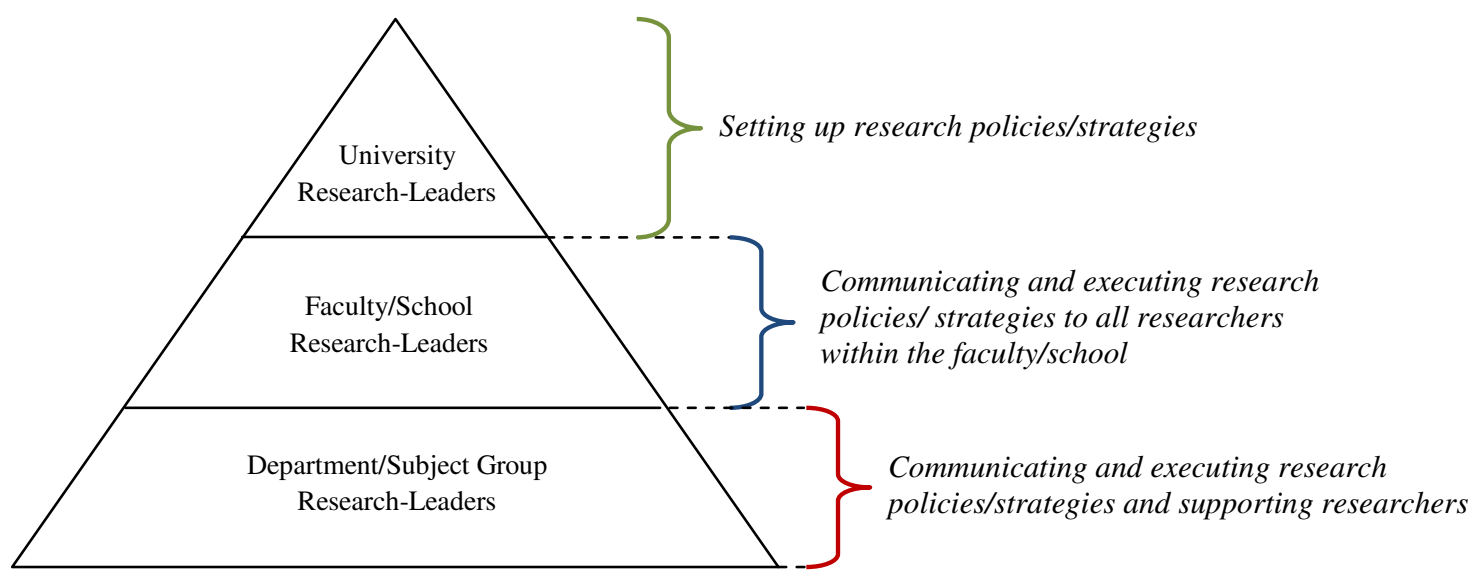

Figure 3: Basic Roles of Research-Leaders at Various Levels

This paper suggests that researchers at different career phase are linked to three types of "driven" approach: (1) self-driven; (2) support-driven; and (3) self \& support-driven. Selfdriven researcher is someone with high self-motivation to do research and do not require specific support from research-leaders - e.g. senior researchers with strong research profiles. Support-driven researcher on the other hand, is someone who requires specific guidance and seeks for inspirations from research-leaders - e.g. early career researchers. Self \& supportdriven researcher is someone in combination of both types. This category could be consist of mid career researchers who is in the middle range of their career, and that they may already 
be self-motivated to do research and do not require support from research-leaders; or they may still be lacking of confidence and seeking for guidance and inspirations from researchleaders.

Researchers also aware they are bearing the risk of losing power when sharing their researchknowledge. This scenario is seen to be more synonyms for senior career researchers, in which their job may jeopardise their positions when sharing more of the tacit knowledge with other researchers. The competitive environment in higher education institutions in terms of research may cause this risk to happen.

"...when we share knowledge we will have to remember how much of it can be let out, how much of the tacit can be shared because when you share the knowledge you will lose your power and you don't monopoly the knowledge anymore." (Early Career Researcher)

\begin{abstract}
"Some people aware the risks that they.re bearing when sharing knowledge, especially tacit knowledge which can be used by others to produce something that they hope to produce. They might think that their research area is something very important for them to move forward and so they don't want to share it with others. So there's a competition." (Senior Career Researcher)
\end{abstract}

Although the list in Table 2 is not exhaustive, it gives an example of the nature of the comments. Higher education institutions were keen on encouraging research-knowledge sharing among researchers despite career phase. However, the most frequently occurring comment shows the need for reliable and effective knowledge-sharing culture within the university, so that less constraint is experienced by researchers to share their researchknowledge. In order for this to happen the university needs to consider improving all the occurred elements.

\title{
6. Implications
}

The results indicate that the types of knowledge shared among researchers from all career phases are varied across the timeline of a research project. Clearly, research proposal and research design are the critical stages for researchers, in which they choose not to share it with other people. The end results of a research project and research publications obviously are the popular stages where both explicit and tacit research-knowledge is shared. This implies that a process view may be needed to understand knowledge sharing. The SECI spiral model by Nonaka and Takeuchi.s (1995) tends to be general in taking into account of process differences. It could be argued that at the difference phase of an activity, the transformation between tacit and explicit knowledge and the level of sharing could be different, thus, different driving mechanism may be needed to facilitate knowledge sharing at different phases.

While presenting some drivers that induces researchers to share knowledge, this paper reveals the "not-to-share" factors that negatively affected research-knowledge sharing within the university. Top of the list is lack of support from research-leaders and senior researchers perceived by researchers at early and middle career stages. This has implication to the university research leaders that an appropriate mechanism and culture need to be established and implemented to facilitate and drive employee to share their knowledge.

This paper demonstrates the basic roles of research-leaders from different levels, showing the professors and/or associate professor as those of which researchers seek support and 
inspiration from. From those findings, three types of researchers have been suggested, linking the cluster of researchers' career phases. This suggests that the leaders who facilitate knowledge sharing may not necessarily the leaders in a formal authoritative role, but those who are perceived expertises in their field. These expertises shall be given power and flexibility to initiate procedure and mechanism to encourage knowledge sharing.

In short, there is a distinctive pattern emerged when research-knowledge, explicit and tacit, is shared among researchers. This depends on the phases of the process and the "to-share" or "not-to-share" factors.

\section{Conclusion}

Effective knowledge sharing is a key activity for organisations. Higher education institutions shoulder noteworthy tasks of developing, cultivating, and inheriting knowledge and passing through to benefit the society globally. This paper examined a specific domain of a researchknowledge sharing. The contribution of this paper is to elaborate the nature of researchknowledge sharing at higher education institution, bridge the gap and enrich the literature.

The drivers for research-knowledge sharing at higher education are broader. Following their main role as academics, researchers predominantly share their research-knowledge to fulfil their academic requirements, like helping the body of knowledge and updating teaching. Similar to what is established in the context of organisational knowledge sharing, this paper also found evidence of the lack of support and inspiration from research-leaders as one of the important "not-to-share" factors that weaken research-knowledge sharing activities. However, the "leadership support" issue in the higher education context is more multifaceted, in which it is linked to the types of researchers and their career phases, as proposed by this paper. Also, this issue varies for research-leaders at different levels, witnessing researchleaders at the department/subject group level, like professors; as much closer to the researcher and whom the researchers need support and inspiration from. Uniquely, the researchknowledge sharing pattern occurs on interval basis, in which research-knowledge is normally shared at the stages of research results and publications. Specifically, each time frame involves different types of knowledge being shared. And finally, this paper uncovers multiple platforms used to share research-knowledge within the university, with a division of three communication types.

It must be noted that the difference of field of research, disciplines and institutions could limit the generalisability of the findings of this study. As this is an explorative study, the patterns emerged from one institution may not apply to other institutions.

\section{Future Study}

This paper reports the first stage of a major research project, which examines researchknowledge sharing in UK Pre- and Post-1992 higher education institutions. 


\section{References}

Aarts, E., Harwig, R., and Schuurman, M. (2001) Ambient Intelligence., in P. Denning (ed.) The Invisible Future, New York: McGraw Hill, pp. 235-50.

Abdullah, H. S. Hassim, A. A. and Chik, R. (2009) Knowledge Sharing in a Knowledge Intensive Organization: Identifying the Enablers., International Journal of Business and Management,Vol.4, No. 4, pp.115- 123.

Akgun, A.E. Byrne, J. Keskin, H. Lynn, G.S. and Imamoglu, S.Z. (2005) Knowledge networks in new product development projects: a transactive memory perspective., Information and Management, Vol. 42, pp.1105-1120.

Alavi, M. and Leidner, D.E. (1999) Knowledge Management Systems: Issues, Challenges, and Benefits., Communications of Association of Information Systems, Vol. 1, No. 7, pp.137.

Alvesson, M. and Karreman, D. (2001) Odd couple: Making sense of the curious concept of knowledge management., Journal of Management Studies, Vol. 38, No. 7, pp.995-1018.

Barth, S. (2000). The power of one. Knowledge Management Magazine, November 2000. Obtained through the Internet:

http://www.destinationkm.com/articles/default.asp?ArticleID=615, [access 19/03/2011].

Bevill, A. R. and Gast, D. L. (1998) Social safety for young children: A review of the literature on safety skills instruction., Topics in Early Childhood Special Education, Vol. 18, pp.222-234.

Blair, D.C (2002) Knowledge Management: Hype, Hope, or Help?., Journal of the American Society for Information Science and Technology, Vol. 53, No. 12, pp.1019-1028.

Callon, M. (1986) Some elements of a sociology of translation: domestication of the scallops and fishermen of St. Brieuc Bay, In Law, J., editor, Power, action and belief. A new sociology of knowledge? London: Routledge, pp.196-233.

Calof, J. L. (2008) Selling competitive intelligence., Competitive Intelligence Magazine, Vol. 11, No. 1, pp.39-42.

Chen, W.S and Hirschheim R. (2004) A paradigmatic and methodological examination of information systems research from 1991 to 2001., Information Systems Journal, Vol. 14, pp.197-235.

Cheol, S.J. (2011) Teaching and research nexuses across faculty career stage, ability and affiliated discipline in a South Korean research university., Studies in Higher Education, pp.1-19, iFirst Article.

Chesbrough, H. (2003a) Open Innovation. Harvard University Press: Cambridge, MA.

Chesbrough, H. (2003b) The era of open innovation. Sloan Management Review Summer, Vol. 35-41.

Choi, B. and Lee, B. (2003) An empirical investigation of KM styles and their effect on corporate performance., Journal of Information and Management, Vol. 40, No. 5, pp.403-417. 
Chong, E.K.M. (2010) Using blogging to enhance the initiation of students into academic research., Computers \& Education, Vol. 55, pp.798-807.

Chow, W. S. and Chan, L. S. (2008) Social Network, Social Trust and Shared Goals in Organizational Knowledge Sharing., Information \& Management, Vol.45, No.7, pp. 458-465.

Darroch, J. and McNaughton, R. (2002) Examining the link between knowledge management practices and type of innovation., Journal of Intellectual Capital, Vol. 3, No. 3, pp.210-22.

Darroch, J. and McNaughton, R. (2003) Beyond market orientation: Knowledge management and the innovativeness of New Zealand firms., Journal of Marketing, Vol. 37, No. 3/4, pp.572-593.

Davenport, T. \& Prusak, L. (1998) Working knowledge, Boston: Harvard Business School Press.

David, P. A., and Foray, D. (2002) An introduction to the economy of the knowledge society., International Social Science Journal, Vol.54, pp9-23.

Eisenhardt K.M. and Martin J.A. (2000) Dynamic capabilities: what are they?, Strategic Management Journal, Vol. 21, No. 10/11, pp.1105-1121.

Gupta, A.K. and Govindarajan, V. (2000) Knowledge management.s social dimension: lessons from Nucor Steel., MIT Sloan Management Review, Vol. 42, No. 1, pp.71-80.

Hawamdeh, S. (2003) Knowledge Management Cultivating Knowledge Professionals, Oxford: Chandos Publishing.

Hsu, C. L., \& Lin, J. C. C. (2008) Acceptance of blog usage: The roles of technology acceptance, social influence and knowledge sharing motivation., Information and Management, Vol.45, No.1, pp. 65-74.

Jarvenpaa, S. Staples, D.S. (2000) The use of collaborative electronic media for information sharing: an exploratory study of determinants., Journal of Strategic Information Systems, Vol. 9, pp.129-154.

Kidwell, J. L., Vander Linde, K. M., \& Johnson, S. L. (2000) Applying Corporate Knowledge Management Practices in Higher Education. Educause Quarterly, 4, 28-33.

Klein, J.H. (2008) Some directions for research in knowledge sharing., Knowledge Management Research \& Practice, Vol. 6, pp.41-46.

Latour, B. (2000) When things strike back: a possible contribution of „science studies. to the social sciences., British Journal of Sociology, Vol.51, pp.107-23.

Levin, D. Z., Cross, R. Abrams, L. C. and Lesser, E. L. (2002) Trust and Knowledge Sharing: A Critical Combination., IBM Institute for Knowledge-Based Organizations, pp.1-9.

Liebowitz, J. (2001) Knowledge management and its link to artificial intelligence., Expert Systems with Applications, Vol. 20, pp.1-6.

Lin, M. J., Hung, S. W., \& Chen, C. J. (2009) Fostering the Determinants of Knowledge Sharing in Professional Virtual Communities., Computers in Human Behavior, Vol.25, No.4, pp.929-939. 
Majchrzak, A., Cooper, L. P., and Neece, O. E. (2004) Knowledge reuse for innovation., Management Science, Vol.50, pp.174-188.

Massey, A.P. Montoya-Weiss, M.M. and O.Driscoll, T.M. (2002) Knowledge Management in Pursuit of Performance: Insights from Nortel Networks., MIS Quarterly, Vol. 26, No. 3.

Metcalfe, A. (2006) Knowledge Management and Higher Education: A Critical Analysis. Hershey, PA: Information Science Publishing.

Neuman , L. (1997) Social research methods: Qualitative and quantitative approaches, Boston: Allyn \& Bacon.

Nonaka, I. and Konno, N. (1998) The concept of „ba.: building a foundation for knowledge creation., California Management Review, Vol.40, pp.40-54.

Nonaka, I. and Takeuchi, H. (1995) The Knowledge Creating Company., Oxford: Oxford University Press.

Nonaka, I. (1994) A dynamic theory of organizationalknowledge creation., Organization Science, Vol.5, No.1, pp.14-37.

Otter, J. (2009) The Philosophy of Research. Report to the Unisa Graduate School of Business Leadership., Unpublished, in Van

Heerden C.N. (2010) Knowledge sharing in a globally dispersed engineering service company.. Research Report presented at the Graduate School of Business Leadership University of South Africa. Obtained through the Internet: http://uir.unisa.ac.za [accessed 20/03/2011].

Sadri, G. and Lees, B. (2001) Developing corporate culture as a competitive advantage., Journal of Management Development, Vol. 20, No. 10, pp.853-859.

Salisbury, M. W. (2003) Putting Theory Into Practice to Build Knowledge Management Systems., Journal of Knowledge Management, Vol. 7, No. 2, pp.128-141.

Schimank, U. and Winnes, M. (2000) Beyond Humboldt? The relationship between teaching and research in European university systems., Science \& Public Policy, Vol. 27, No. 6, pp.397-408.

Shapira, P. Youtie, J. Yogeesvaran, K. and Jaafar, Z. (2005) Knowledge Economy Measurement: Methods, Results and Insights from the Malaysian Knowledge Content Study.. Paper Proceedings of the Triple Helix 5 Conference on New Indicators for the Knowledge Economy. Turin, Italy.

Shin, J.C. (2009) Building world-class research university: The Brain Korea 21 project., Higher Education, Vol. 58, No. 5, pp.669-88.

Silverman, D. (1994) Interpreting Qualitative Data: Methods for Analysing Talk, Text and Interaction, London: Sage Publications.

Simonin, B.L. (1997) The importance of Collaborative Know-How: An Empirical Test of the Learning Organisation., Academy of Management Journal, Vol. 40, No. 5, pp.1150-1174. 
Snowden, D. (2008) Rendering knowledge: the seven principles of knowledge management., Obtained through the Internet:

http://www.cognitiveedge.com/blogs/dave/2008/10/rendering_knowledge.php [accessed 19/09/2011].

Sosik, J. J. and Godshalk, V. M. (2000) The role of gender in mentoring. Implications for diversified and homogeneous mentoring relationships., Journal of Vocational Behavior, Vol. 57, pp.102-122.

Stanley, E. C., and Patrick, W. J. (1998) Quality Assurance in American and British Higher Education: A Comparison., In, Quality Assurance in Higher Education: An International Perspective, ed. G. H. Gaither. San Francisco: Jossey Bass

Syed-Ikhsan S.O.S. and Rowland, F. (2004) Benchmarking knowledge management in a public organisation in Malaysia. Benchmarking., An International Journal, Vol. 11, No. 3, pp.238-266.

Thomke, S. (1998) Managing experimentation in the design of new products., Management Science, Vol. 44, pp.743-762.

Thompson, M. P. A., and Walsham, G. (2004) Placing knowledge management in context., Journal of Management Studies, Vol. 41, pp.725-747.

Van den Hooff, B. and Van Weenen, F.D.L. (2004) Knowledge sharing in context: the influence of organizational commitment, communication climate and CMC use on knowledge sharing., Journal of Knowledge Management, Vol. 8, No. 6, pp.117-30.

Von Hippel, E. (1988) The Sources of Innovation, Oxford University Press.

Walsham, G. (1995) Interpretive case studies in IS research: nature and method., European Journal of Information Systems, Vol. 4, No. 2, pp.74-81.

Wang, S., \& Noe, R. A. (2010) Knowledge sharing: A review and directions for future research., Human Resource Management Review, Vol.20, pp.115-131.

Widen-Wulff, G. and Suomi, R. (2003) Building a Knowledge Sharing Company - Evidence From the Finnish Insurance Industry. Proceedings of the 36th Hawaii International Conference on System Sciences. Big Island, Hawaii.

Widen-Wulff, G. and Suomi, R. (2007) Utilization of Information Resources for Business Success: The Knowledge Sharing Model., Information Resources Management Journal, Vol. 20, No. 1, pp.46-67.

Yin, R.K. (1984) Case Study Research: Design and Methods, London: Sage Publications.

Zelkha, E., and Epstein, B. (1998) From Devices to 'Ambient Intelligence': The Transformation of Consumer Electronics., Presentation at the Digital Living Room Conference (June 1998), Philips. 